\title{
Characterization of the chromium retention potential of non polluted aquifer solids in an industrial site
}

Caroline Reynal (1), Monika A.M. Kedziorek (1), Claire Rollin (2), Alain C.M. Bourg (1)

(1) : Environmental Hydrogeochemistry Group, University of Pau (UPPA), Dept. of Earth Sciences, BP 1155, 64013 Pau Cedex, France (tel. 05598068 97, fax 05598012 92, Caroline.Reynal@univ-pau.fr)

(2) : INERIS, Parc Technologique ALATA, BP2, 60550 Verneuil en Halatte, France

\begin{abstract}
A hydrogeochemical study of an industrial site where sulfuric acid and copper sulfate ("bouillie bordelaise") are manufactured showed that the phreatic aquifer is contaminated by copper, sulfate, chromium, arsenic and has an acid $\mathrm{pH}$. Field observations and laboratory experiments, both necessary if we are to understand the processes controlling tranfers at the solid-liquid interface, were used to investigate the behaviour of chromium. In the field, monitoring the mixing of polluted and unpolluted water with a conservative tracer, we shows that chromium disappears from solution. In the laboratory, the potential for retention of dissolved chromium by an unpolluted aquifer solid was studied as a function of $\mathrm{pH}$, with and without a complexing agent. Adding high concentrations of a complexing agent, EDTA, mobilizes the previously fixed chromium at basic $\mathrm{pH}(90 \%)$. Addition of $\mathrm{Cr}(\mathrm{III})$ with EDTA gathered, sorption is greatest $(50 \%)$ for neutral and basic $\mathrm{pH}$ values. Unpolluted aquifer solids have a high sorption capacity for $\mathrm{Cr}$ (III). However, adding a complexing agent significantly mobilizes the chromium. Sorption of the complexed chromium is also considerably decreased. There should, therefore, be little risk of immediate chromium pollution in the absence of dissolved complexing agents, as long as the $\mathrm{pH}$ of the system is neutral.
\end{abstract}

\section{INTRODUCTION}

An industrial plant located in Bordeaux, France, was investigated : the phreatic fill aquifer is probably contaminated due to the manufacture of "bouillie bordelaise" (copper sulphate), processes involving the chemical treatment of copper and the use of pyritic minerals for the production of sulfuric acid.

The objective of the study is double (i) investigate the retention potential of chromium by a non polluted solid, obtained from a core in the periphery of the site and (ii) understand the mechanisms controlling the solubility and, therefore, the potential transport of chromium in a contaminated aquifer. Three approaches were used : (i) analysis of water samples collected on the site, (ii) sorption experiments in closed reactors of chromium (III) with or without complexing agent by an unpolluted solid, and (iii) modelling of chromium fixation by a unpolluted solid.

\section{THE INDUSTRIAL PLANT : regional setting, activities and contamination}

In the French Atlantic coast, the studied area is an industrial plant, located within the city of Bordeaux, near the Garonne river. The factory has manufactured "bouillie bordelaise" since the early 1900's and initially also produced sulfuric acid. Pyritic minerals (stored on the ground) were used to manufacture this acid. In 1991, a preliminary study revealed low $\mathrm{pH}$ values and high concentrations in sulfate, copper, chromium and arsenic in the aquifer [1]. In this study we investigated the phreatic aquifer underlying the site; it is five - meter thick, located in an area of backfill. 


\section{MATERIALS AND METHODS}

\subsection{Sampling and analysis}

The site is equipped with piezometers and multi-levels samplers. Boreholes were drilled in 1991, 1999 and 2000. Solids were obtained as cores during drilling for further experiments. Four campaigns were carried out to sample water in the phreatic aquifer. The solid studied here comes from a core drilled in the unpolluted area of the site.

\subsection{Batch experiments}

The sorption of chromium was studied using batch experiments. Soil suspensions, 10 g. $\mathrm{L}^{-1}$, were equilibrated in $10^{-2}$ mol.L $\mathrm{L}^{-1} \mathrm{NaNO}_{3}$ with added acid (HNO3) or base $(\mathrm{NaOH})$ to give $\mathrm{pH}$ values ranging from 2 to 12 . Chromium (III) was added to provide a concentration of $2.10^{-6} \mathrm{~mol}$. $\mathrm{L}^{-1}$. A set of experiments are carried out on the unpolluted solid, with or without the complexant EDTA : (i) the soil suspension was equilibrated with $\mathrm{Cr}$ (III) for three days; (ii) the suspension is spiked with $\mathrm{Cr}$ (III). After three days, $10^{-2}$ mol. $\mathrm{L}^{-1}$ of EDTA is added; (iii) the solid suspension is spiked with $\mathrm{Cr}$ (III) in presence of $2.10^{-6}$ mol. $\mathrm{L}^{-1}$ of EDTA (equilibrium time : three days).

\subsection{Modeling of chromium fixation by a unpolluted solid.}

PHREEQC, a geochemical transport model, is used to simulate the sorption of $\mathrm{Cr}$ (III) in the absence of EDTA on the unpolluted solid [2].

\section{RESULTS}

\subsection{Chromium concentration in groundwater}

For all of the piezometers and multi-level samplers, the $\mathrm{Cr}$ concentration in the groundwater, ranges from $10^{-5}$ to $10^{-8}$ mol. $\mathrm{L}^{-1}$ (figure 1.). The concentration of chromium is highly dependent on $\mathrm{pH}$. It is greatest for acid $\mathrm{pH}$. Above $\mathrm{pH} 6$, the concentration is quite constant.

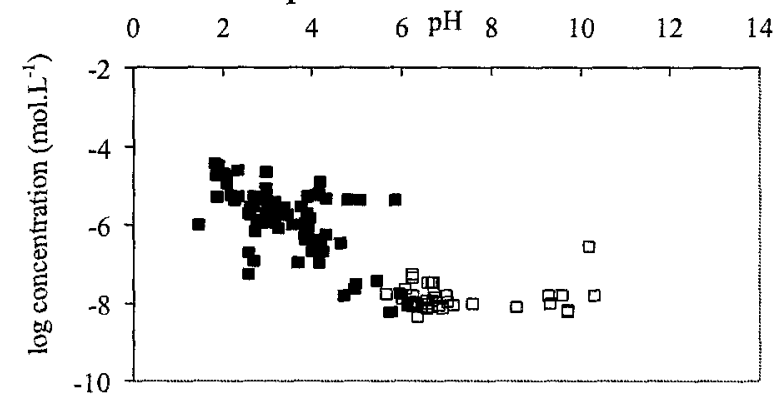

Figure 1. Dissolved total chromium in the sampling points of the site 


\subsection{Index of mixing between two different waters}

Sulfate was chosen as an index of mixing between the polluted and unpolluted water [3]. By comparing for each sampling point, the index mixing with the dissolved total chromium concentration, chromium seems to disappear from the aquifer water in the sampling devices located in the unpolluted area and seems to be appear in the sampling devices located in the polluted area (figure not shown). The choice of sulfate as mixing index should probably be validated.

\subsection{Removal of $\mathrm{Cr}$ (III) from solution in the presence of an unpolluted solid and chromium fixation in presence of EDTA}

Chromium(III) removal is maximal for neutral $\mathrm{pH}$ (4 to 8) (figure 2.a). It can be due to adsorption or precipitation. It increases with $\mathrm{pH}$. From $\mathrm{pH} 9$ to 11, chromium is slightly less removed. For these same $\mathrm{pH}$ values, solubilization of organic carbon from the solid increases (figure 2.b). Complexation by organic matter could keep chromium in solution.

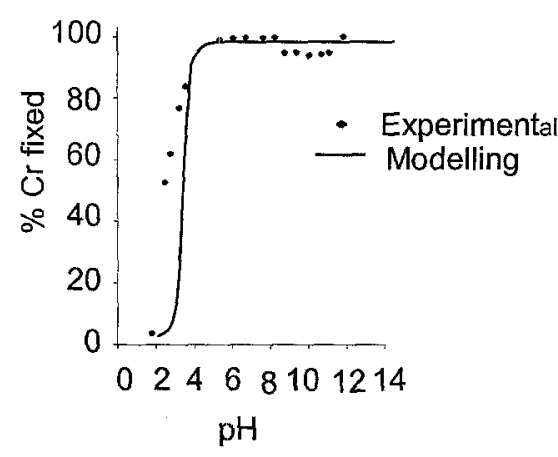

a)

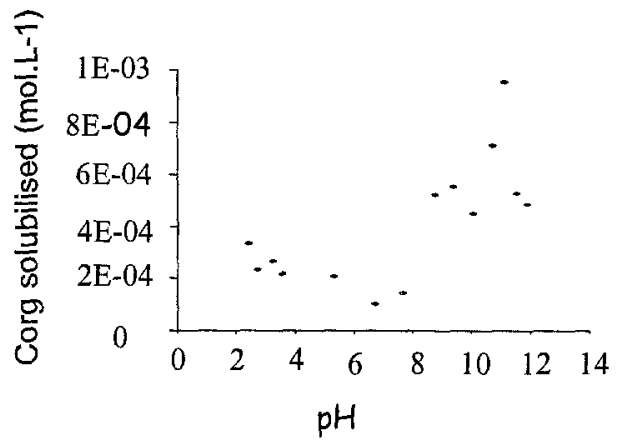

b)

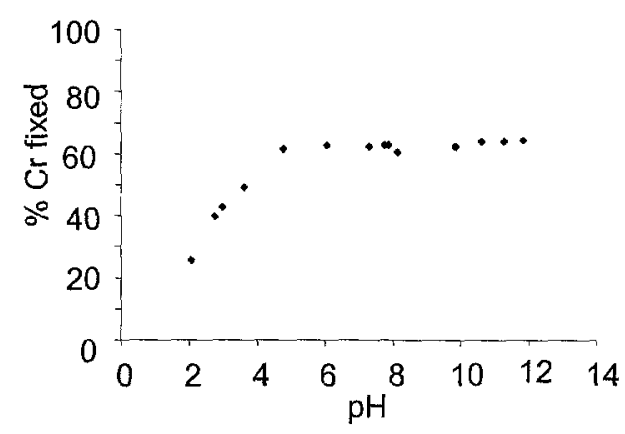

c)

Figure 2. Cr(III) fixation on the unpolluted solid et organic carbon solubilization from the solid (figure $3 . a, b)$ and chromium fixation in presence of EDTA (figure 3.c)

A solution of $\mathrm{Cr}(\mathrm{III})$ and EDTA, both $\left(2.10^{-6} \mathrm{~mole} / \mathrm{L}\right)$ is added to the unpolluted solid suspension. The fixation increases progressively at acid $\mathrm{pH}$ and reaches a maximum for $\mathrm{pH}>4$. The sorption profile seems similar to that obtained in the absence of EDTA (figure 2.c). However, fraction removed from solution is strongly decreased (from $100 \%$ to $60 \%$ ).

\subsection{Chromium(III) fixation onto an unpolluted solid and mobilization by subsequent addition of EDTA}

The addition of EDTA after contact of dissolved $\mathrm{Cr}$ (III) with the solid provides a solubility profile similar to that of the previous experiments (figure 3.), but more marked. This supports the hypothesis of chromium complexation by organic matter.

Besides, between $\mathrm{pH} 4$ and 6 , chromium is still fixed onto the solid but with a decrease of $20 \%$ (compared to the $100 \%$ fixation of free chromium).

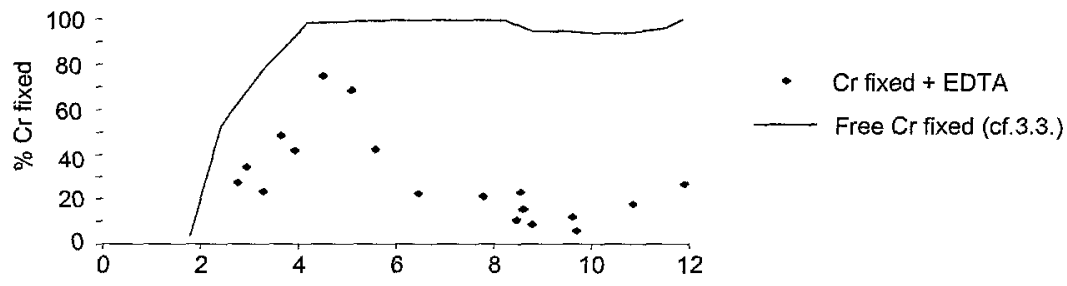

Figure 3. Chromium behavior in the absence of EDTA and in the presence of subsequent addition of EDTA 
This minimum of mobilisation could be due to (i) the competition between complexation and adsorption, (ii) readsorption of chromium as ternary surface complexes, or (iii) complexation of Fe by EDTA, that would decrease its complexing power for chromium [4], [5].

\subsection{Modelling free chromium(III) fixation}

The experimentally observed chromium uptake by this solid is best represented by fixation at the same time, on iron hydroxide, silica and alumina (figure 2.a). We tested both adsorption and precipitation. Adsorption seems to be the best hypothesis in view of modelling result. The hypothesis of complexation by organic matter could not be modelled because of the lack of thermodynamics constants.

\section{Conclusion}

The unpolluted solid has a high capacity to remove $\mathrm{Cr}$ (III) from solution. The $\mathrm{Cr}$ (III) fixation is maximal for basic $\mathrm{pH}$. However the presence of complexing agents decreases significantly its fixation at basic $\mathrm{pH}$ values.

Physico-chemical changes (addition of dissolved complexing agents) could increase the risk of chromium pollution.

\section{Acknowledgements}

We thank ADEME, INERIS and the European Union (ERDF Program) for funding this study, AGTROL International for access to their site and Emmanuel Landat, Jerôme Ré, Olivier Etchebers and Ian Bourg for help with sampling and analysis.

\section{References}

[1] Burgeap, La Cornubia S.A. Bordeaux (33), (1992), Rapport d'activité n R1144-A.2877/391089.

[2] Parkhurst D. L. and Appelo C. A. J., 1995, User's guide to PHREEQC, Water Resources Investigations Report 95-4227, (U. S. Geological Survey, Lake Wood, Colorado, 1995)

[3] Bourg A. C. M. and Bertin C., Environ. Sci. Technol. 27 (1993) pp. 661-666.

[4] Norwell W. A. and Lindsay W. L., SSSAP, 33 (1969) pp. 86-91.

[5] Davis A. P. and Hupadhyaya M., Water Res. 30, (1996) pp. 1894-1904. 